УДК 81.23

\title{
ТЕКСТООБРАЗУЮЩАЯ ФУНКЦИЯ АССОЦИАТИВНЫХ ПОЛЕЙ
}

ХОМИЧ В. В.

аспирант

Минский государственный лингвистический университет viktoriakhomich@gmail.com

\begin{abstract}
В статье рассматривается ассоциативная структура текста короткого рассказа на английском языке The Legend of the Christmas Tree L. Wheelock (“Легенда Рождественского дерева"), которая представляет собой модель текста, отражающую семантические связи между его словесно-ассоциативными полями. Приводятся также определения ассоциативного поля слова и ассоциативного поля текста; рассматривается их лексическое наполнение и структура. Ключевые слова рассматриваются как основа текстового ассоциативного поля. Представлены ассоциативные поля отдельных ключевых слов, а также текстовое ассоциативное поле всего рассказа. Материалом для построения ассоциативных полей выступают ключевые слова текста и связанные с ними на основании ассоциативносмысловой близости лексические единицы. Описывается семантическое ядро текста, играющее ведущую роль в процессе текстообразования. Доказывается, что ни одно из ассоциативных полей не существует обособленно, все ассоциации тесно связаны и между собой внутри полей, и с основной идеей текста, тем самым создавая его ассоциативную структуру. Выявляются текстообразующие направления ассоциирования, связанные с функционированием словесно-ассоциативных полей в тексте. Подтверждается идея о том, что имеющийся в сознании говорящего лексикон должен быть готов к порождению текстов. Показывается насколько важен процесс ассоциирования при создании текста и при его восприятии, какую роль он играет в диалоге автора с читателем.
\end{abstract}

Ключевые слова: текст, ассоциативное поле, ассоциативная структура, семантическое ядро, ключевое слово, ассоциация, текстообразование.

\section{ТЕКСТОТВІРНА ФУНКЦІЯ АСОЦІАТИВНИХ ПОЛІВ}

ХОМИЧ В. В.

аспірант

Мінський державний лінгвістичний університет viktoriakhomich@gmail.com

У статті досліджено асоціативну структуру тексту короткого оповідання англійською мовою The Legend of the Christmas Tree L. Wheelock (“Легенда Різдвяного дерева”). Доведено, що асоціативна структура тексту відображає семантичні зв’язки між його словесно-асоціативними полями. 3'ясовано лексичне наповнення й структуру асоціативного поля слова і асоціативного поля тексту.

Звернено особливу увагу на ключові слова як основу текстового асоціативного поля. Представлені асоціативні поля окремих ключових слів, а також текстове асоціативне поле усієї розповіді. Матеріалом для побудови асоціативних полів слугують ключові слова тексту і пов'язані з ними на підставі асоціативно-смисловий близькості лексичні одиниці.

Описано семантичне ядро тексту, що відіграє провідну роль у процесі текстотворення. Установлено, що жодне з асоціативних полів не існує відокремлено, усі асоціації тісно пов'язані і між собою всередині полів, і з основною ідеєю тексту і в такий спосіб формують його асоціативну структуру.

Виявлено текстотвірні напрямки асоціювання, пов'язані з функціонуванням словесно-асоціативних полів у тексті. Обгрунтовано ідею про те, що наявний у свідомості мовця лексикон повинен бути готовий до породження текстів. 
Наголошено, що процес асоціювання дуже важливий для створення тексту і для його сприйняття, саме він відіграє важливу роль у діалозі автора $з$ читачем.

Ключові слова: текст, асоціативне поле, асоціативна структура, семантичне ядро, ключове слово, асоціація, текстотворення.

TEXT-FORMING FUNCTION OF ASSOCIATIVE FIELDS

KHOMICH Victoriia Victorivna

$\mathrm{PhD}$ student

Minsk State Linguistic University viktoriakhomich@gmail.com

Introduction. Text-forming function of lexico-stylistic devices in literary texts is always in the center of philological investigations. The paper focuses on the text-forming function of associative fields in short story The Legend of the Christmas Tree by L. Wheelock.

Purpose. The paper aims at modelling associative fields, which perform text-forming function. The main interest is concentrated on a model of the text, which reflects the semantic links between its verbal-associative fields.

Methods. The research is grounded on the method of contextual analysis, the method of modelling the semantic fields, theory of imaginary fields, textual interpretative analysis.

Results. The definitions of the word-associative field and the associative field of the text are presented in the paper. Their lexical content and structure are examined. Key words are considered as the basis of the text associative field. The paper has the description of the associative field composed by keywords, as well as the textual associative field of the whole story. The material for constructing associative fields is the following: the keywords of the text and the lexical units associated with them on the basis of associative-semantic proximity. The semantic core of the text, which plays a leading role in the process of text formation is described.

Conclusions. It is proved that none of the associative fields exist separately, all associations are closely related to each other within the fields, and to the basic idea of the text, thereby creating its associative structure. The text-forming directions of the associative process connected with the functioning of verbal-associative fields in the text are revealed. The idea that the lexicon in the mind of the speaker should be ready for the generation of texts is onfirmed. The importance of the associative process by text-formation and perception is analyzed as well as its role in the author's communication with the reader.

Keywords: text, associative field, associative structure, semantic core, keyword, association, text-forming function

Постановка проблемы. Ассоциативность является важным и наиболее значимым коммуникативным свойством слова, поскольку речемыслительная деятельность человека имеет ассоциативный характер: как только в сознании носителя языка появляется какая-то идея, мысль, образ, они влекут за собой появление других, новых идей, мыслей и образов, семантически связанных с ними. Рассмотрение лексической структуры текста в ассоциативном аспекте является чрезвычайно важным. Под ассоциативной структурой текста понимается “модель, отражающая связь основных направлений ассоциирования, объективно стимулированных в тексте определенной системой знаков и знаковых последовательностей в процессе текстообразующей и интерпретационной деятельности субъектов" (Карпенко, 2009 , с. 112). Центральным звеном ассоциативной структуры текста является его ассоциативное поле, основой которого выступают ключевые слова.

Цель данной статьи - выявление текстообразующего потенциала ключевых слов и образующихся вокруг них ассоциативных полей на материале короткого англоязычного pacсказа The Legend of the Christmas Tree L. Wheelock (“Легенда Рождественского дерева”).

При помощи ассоциаций автор художественного произведения создает свой собственный, воображаемый мир и приглашает в него читателя. Читатель же, в свою очередь, пытается 
перенести этот мир в свою реальность, провести аналогии со своей жизнью, найти что-то общее с описываемыми в рассказах событиями, сравнить себя с главными героями. Это все становится возможным благодаря ассоциациям, поскольку ментальный лексикон человека обладает ассоциативным потенциалом, который активируется в момент получения импульса (стимула) и становится готовым к производству своих собственных идей и смыслов, существующих в тексте (Клименко, 2002).

Наиболее ассоциативным считается художественный текст, поскольку ему свойственна образность, и он взывает не только к сознанию читателя, но и к его эмоционально-чувственной стороне. И. Р. Гальперин говорит о том, что “ассоциации в художественном произведении не возникают спонтанно. Они результат творческого процесса, в котором отдаленные, не связанные логическими скрепами представления приобретают вполне понятные связи между описываемыми явлениями" (2006, с. 79).

Анализ последних исследований и публикаций. Известным фактом является и то, что текст художественного произведения представляет собой продукт речемыслительной деятельности человека, а текстовое ассоциативное поле формируется в зависимости от контекста. Ассоциативная деятельность читателя не ограничивается восприятием текста в целом. Элементы и структура текста, личность автора, сюжет, композиция, идея и образы влияют на ассоциативное видение текста. Каждый читатель интерпретирует текст по-своему. Но в тексте всегда есть ключевые слова, понятия, которые в процессе прочтения каждый выделяет сам на основании своих личных переживаний, опыта, восприятия мира, уровня образованности, развитости воображения. Всегда в тексте есть и то, что очевидно для большинства читателей, и то, что могут увидеть лишь некоторые из них, и то, что будет абсолютно новым для всех.

Основная идея текста задает направление ассоциирования, и каждый исследователь при анализе того или иного текста опирается на те принципы, согласно которым он выделяет ключевые слова и моделирует их ассоциативные поля. Моделируемые поля в свою очередь отражают ассоциативную природу ключевых слов и разнообразие вызываемых ими ассоциаций. Это разнообразие обусловлено ещё и тем, что “стимулами для ассоциативной деятельности читателя в данном случае служат не только текст в целом, его элементы и структура, но и личность автора, сюжет, композиция, идеи и образы, присутствующие в тексте” (Верескун, 2012, с. 126).

Текстовые ассоциативные поля играют важную роль в лексической структуре текста, поскольку она состоит из ключевых слов и их ассоциативного окружения и выявляется в ходе анализа текста с точки зрения его ассоциативного наполнения. При организации лексической структуры текста и его лексико-семантической упорядоченности в процессе его порождения текст рассматривается “как сложно организованная сеть ассоциатов, в образовании которой участвуют ассоциативно-смысловые поля ключевых слов, значимые для познавательной деятельности адресата" (Болотнова, 2003, с. 34). Однако А. Е. Супрун указывал на то, что лексическая структура текста определяется отбором слов для данного текста, который происходит на основании тематических проблем, освещенных в нем. Отбор слов и их значений в тексте чрезвычайно важны для его лексической структуры, одним из главных компонентов которой являются ассоциативные поля, содержащие тематические группы и тематически организованные цепочки слов, возникающие согласно закономерностям построения текста и внутренней стороны его лексической организации (Супрун, Клименко, 2017).

Текст - это явление динамичное, которое всегда развивается с учётом окружающей действительности. Поэтому и лингвисты, и психологи, и психолингвисты уделяют большое внимание созданию и восприятию текста как части окружающего нас мира. Стимулом к созданию текста является окружающая действительность, сама жизнь, которая ставит проблемы и формирует мотивы. 
Многие исследователи-лингвисты предлагают в качестве текстообразующих элементов рассматривать ключевые слова текста и слова, с ними ассоциирующиеся, то есть входящие в их словесно-ассоциативное поле.

В ряде работ Н. С. Болотновой, Ю. Н. Караулова, А. Е. Супруна, А. П. Клименко отмечается, что коммуникативные свойства слова, включая его текстообразующие возможности, обусловлены его ассоциативными связями. Эти ассоциативные связи можно рассмотреть внутри ассоциативных полей, создаваемых вокруг ключевых слов рассказа.

Под ассоциативным полем, вслед за А.П. Клименко, мы понимаем все слова - реакции на заданное слово-стимул (Клименко, 1974). Слово-стимул - это ключевое слово в тексте, поскольку именно оно является стимулом к ассоциативной деятельности автора и читателя. Ассоциативное поле слова отражает его коммуникативный потенциал, включая текстообразующие возможности (Болотнова, 2003). Однако наряду со словесным ассоциативным полем, различают и текстовое ассоциативное поле, под которым понимается “система стимулированных текстом в сознании адресата вербальных ассоциаций, организованных по принципу поля, имеющего ядро (наибольшие частотные ассоциации) и периферию” (Болотнова, 2003, с. 278). Эту систему вербальных ассоциаций и представляют все ассоциативные поля выбранных ключевых слов в тексте.

Изложение основного материала исследования. На примере небольшого художественного рассказа на английском языке The Legend of the Christmas Tree (“Легенда Рождественского дерева”) L. Wheelock (Л. Уиллок) рассмотрим более подробно текстообразующую направленность словесно-ассоциативных полей.

The Legend of the Christmas Tree (“Легенда Рождественского дерева”) - это трогательная легенда о доброте маленьких детей, рассказ о том, как дети приютили голодного и замерзшего странника холодной зимой, и в знак благодарности он подарил им Рождественское дерево. Основной темой рассказа выступает история Рождественского дерева, главной идеей - доброта и вознаграждение за добрые дела.

Текст этого художественного произведения создается вокруг четырех подтем, затрагиваемых автором:

- добрые маленькие дети, приютившие ребенка-странника;

- ребенок-странник в холодную зимнюю ночь;

- маленький странник после его знакомства с детьми;

- Рождественское дерево, подаренное детям.

Основой каждой из этих подтем в тексте рассказа являются ключевые слова: child, Christ Child, place, tree и cold, каждое из которых формирует вокруг себя ассоциативное поле из тех слов, которые в тексте ассоциируются друг с другом.

Каждая подтема представляет собой текстовое ассоциативное поле, создаваемое вокруг ключевого слова и наполненное словами, семантически связанными и с ключевыми словами, и между собой.

Представим набор ключевых слов рассматриваемого художественного текста и слов, с ними ассоциирующихся, в виде следующей таблицы:

\begin{tabular}{|l|l|}
\hline child & $\begin{array}{l}\text { Christ Child, children, stranger, band of children, soft voice, little, kind, good, } \\
\text { cold, warm, tired, ran, cried, shoes, garments, }\end{array}$ \\
\hline Child Christ & $\begin{array}{l}\text { cold, hungry, shivering, tired, warm, little stranger, child } \\
\text { ragged, hungry, sweet, peace, happiness }\end{array}$ \\
\hline cold & warm, child, garments, winter, night, outside, shivering, hungry \\
\hline place & world, house, fire, supper, bed, door, outside, bench, seat \\
\hline tree & $\begin{array}{l}\text { Christ Child, year, winter, fir tree, branch, planted, ground, grew, rich fruit, } \\
\text { great, wonderful, golden }\end{array}$ \\
\hline
\end{tabular}


В тексте этого рассказа ассоциативное поле ключевого слова child функционирует в качестве основного текстового ассоциативного поля рассказа, поскольку оно реализует три первые из вышеназванных подтем.

Основная идея текста, легенда о происхождении Рождественского дерева, история о доброте и отзывчивости реализуется при помощи образов small children и Christ child. Описание образов главных героев и создает вокруг себя текст, поскольку между лексическими единицами в ассоциативных полях этих слов возникают семантические связи, не только отражающие главную идею рассказа, но и дающие читателю возможность задуматься над текстом и глубже понять главный смысл произведения.

Так как в тексте выделяется не одно, а несколько ключевых слов, то для понимания основной идеи необходимо установить тесную связь между ассоциативными полями этих слов. Все они связаны не только смысловой близостью с основной темой рассказа, но и с лексическими средствами ее выражающими. Например, Child Christ и Christmas Tree традиционно связаны между собой во многих произведениях литературы и искусства, этот образ присутствует в сознании многих из нас, поэтому, еще не дочитав легенду до конца, мы ее предвосхищаем, предчувствуем и ждем, какова будет ее интерпретация в данном тексте. То, что есть в нашем сознании, зачастую отражено и в художественных текстах, поскольку существуют стереотипные ассоциации с общепринятыми предметами и явлениями, описание которых и помогает авторам создавать тексты, близкие и понятные читателям.

В работах А. П. Клименко не раз отмечалось, что лексикон как часть языкового устройства должен быть готов к порождению текстов. Такая готовность должна обеспечиваться “устройством лексикона в сознании говорящего". На этом и основывается механизм лексического ассоциирования $(1974,2002)$. А вот как именно лексикон устроен в сознании говорящего, остается загадкой, которую ученые-психолингвисты пытаются разгадать уже давно.

Как и все слова в языке, слова в тексте обладают ассоциативными связями, которые обнаруживаются при создании словесно-ассоциативных полей текста. И если ассоциативные поля в речи не ограничиваются одной темой, ассоциирование идет по разным направлениям, то использование слова в тесте накладывает определенные ограничения на его значение. Текстовые ассоциативные поля ограничены заданной темой и основной идеей текста.

Тема холодной зимы и душевных переживаний проходит через весь рассказ. И поскольку в каждом тексте есть семантическое ядро, создающееся вокруг главной темы и идеи рассказа, то в рассматриваемом тексте оно представлено ключевыми словами рассказа, а именно словами, в которых заключена основная мысль автора и его творческий замысел. Ассоциативные поля, образованные вокруг выбранных ключевых слов, будут теми элементами, которые образуют вокруг этого семантического ядра текст. Графически это представлено на рисунке 1 .

Рисунок 1 представляет собой семантическое ядро текста, которое является основным элементом в процессе текстообразования. В его состав входят ключевые слова, под которыми понимаются основные лексические единицы, влияющие на образование смысла создаваемого текста (child, place, stranger, cold, tree), и тематически связанные с ними ассоциации, как стереотипные (cold -winter, shivering), так и единичные авторские (cold hungry, darkness). В зависимости от той идеи, которую автор хочет донести, и формируется текст вокруг этого ядра. Для этого автор выбирает те лексические средства, которые будут отражать его идеи, те слова, при помощи которых он сможет передать в тексте произведения свои мысли и чувства. 


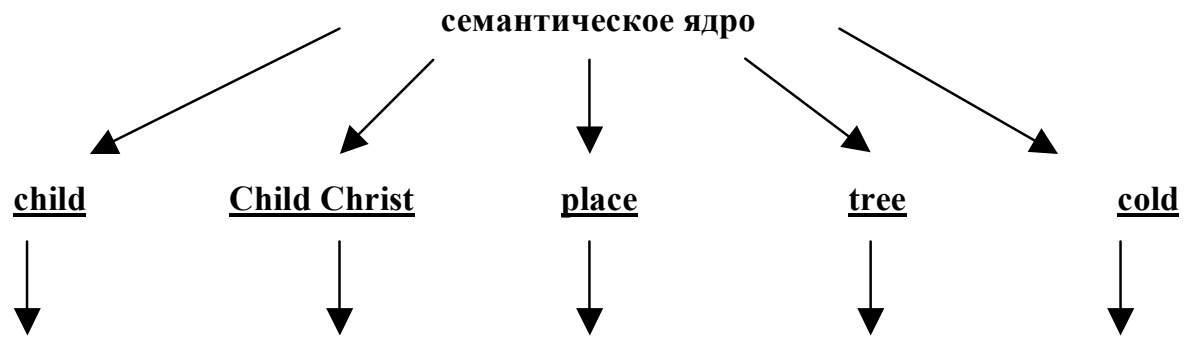

two little timid knock at children; the door; child with no shoes; child shivering with cold; children cried; children in shining garments; kind children; Christ Child; bring happiness to all children; a child with no shoes; cold, hungry and shivering; tired with cold; warm himself; little stranger; the Stranger Child; place by the fire; outside in the cold and darkness; warm seat; hard bench; approaching the house; wandering through the world; near the door; every year; give rich fruit; broke a branch; the fir tree; near the door; planted it in the ground; the branch grew into a great tree; bore wonderful golden fruit; cold winter's night; the cold and the darkness;

Рис. 1

Рисунок 1 представляет собой семантическое ядро текста, которое является основным элементом в процессе текстообразования. В его состав входят ключевые слова, под которыми понимаются основные лексические единицы, влияющие на образование смысла создаваемого текста (child, place, stranger, cold, tree), и тематически связанные с ними ассоциации, как стереотипные (cold -winter, shivering), так и единичные авторские (cold-hungry, darkness). В зависимости от той идеи, которую автор хочет донести, и формируется текст вокруг этого ядра. Для этого автор выбирает те лексические средства, которые будут отражать его идеи, те слова, при помощи которых он сможет передать в тексте произведения свои мысли и чувства.

По утверждению Н. С. Болотновой, “ассоциативное поле текста включает не только реакции на текст в целом, но и на отдельные лексические единицы, выделенные в нём, иначе говоря, ассоциативное поле слов в той или иной степени входит в ассоциативные поля текста" (2003, с. 20). На представленном рисунке видно, как из ассоциативных полей отдельных слов создается ассоциативное поле всего текста анализируемого рассказа. В центре рисунка семантическое ядро, основа текста; далее выделены все его ключевые слова, под которыми приведены ассоциирующиеся с ними лексические единицы. Сразу отметим, что ключевые слова семантически тесно связаны не только со своими ассоциациями, но и между собой: child Christ child - cold - place - tree. По тексту рассказа видно, что эти ключевые слова идут друг за другом, участвуя в описании происходящих событий. Так, образ маленьких детей в начале рассказа представлен ключевым словом child и такими ассоциациями, как: Christ Child, children, band of children, little, kind, good, warm, ran, cried. Следующий образ Christ Child описывается при помощи таких словесных ассоциаций: stranger soft voice cold ragged, hungry, tired shoes, garments, sweet, peace, happiness. Далее описывается место событий: world, house, fire, supper, bed, door, outside, bench, seat и Рождественское дерево, которому посвящена легенда: Christ 
Child, year, winter, fir tree, branch, planted, ground, grew, rich fruit, great, wonderful, golden. Многие из ассоциаций, входящих в ассоциативные поля этих ключевых слов, совпадают: children, little stranger, warm, cold другие.

Рассказ The Legend of the Christmas Tree L. Wheelock (“Легенда Рождественского дерева”) очень короткий, и именно повторы и частое употребление синонимичных слов позволяет автору в таком небольшом тексте передать несколько идей и показать и поведение маленьких детей во время холодной зимы, и их душевную доброту к странствующему ребенку, и вознаграждение за их доброту - Рождественское дерево.

На рисунке видно, что семантическим ядром текста анализируемого рассказа выступают ключевые слова child, Christ Child, place, tree и cold. Использование в тексте рассказа каждого из этих слов влечет за собой появление не только отдельных новых слов, но и словосочетаний, которые впоследствии организуются в предложения и в связный текст. Таким образом, процесс текстообразования начинается с возникновения в сознании автора-создателя ассоциаций, связанных с описываемым событием или явлением. Для создания текста эти ассоциации должны быть связаны между собой и по смыслу, и тематически.

Реализация семантического и эмоционально-экспрессивного потенциала этого ассоциативнообразного ядра осуществляется путем ассоциативных связей, возникающих внутри поля, ассоциативно сопряженных с ключевыми словами, составляющими семантическое ядро pacсказа. Слово child (ребенок) традиционно имеет положительную коннотацию, и с ним обычно ассоциируется всё доброе, нежное, маленькое. Образная актуализация ассоциативных признаков смысла в семантической структуре значения слова child позволяет автору создать вокруг него словесно-ассоциативное поле, представленное следующими словосочетаниями: two little children, child with no shoes, child shivering with cold, children cried, children in shining garments, kind children, Christ Child, bring happiness to all children. По такому же принципу создаются и остальные текстовые ассоциативные поля. Все вместе они способны передать содержание текста и являются его основой, поскольку лексическое ассоциирование имеет текстообразующую направленность. Ассоциативное поле исследуемого рассказа структурируется по стратегиям ассоциирования: child $\rightarrow$ Christ Child $\rightarrow$ Christmas Tree.

Это короткий рассказ, но, несмотря на небольшой объем лексических единиц, задействованных в тексте, он построен логически, он является связным и завершённым, и его главная идея раскрывается четко и однозначно. Важность и значимость ассоциатвных полей при текстообразовании и реализации основных свойств текста - целостности и связности очевидна. Важны они и для передачи информации в процессе коммуникации, поскольку на ассоциировании основываются такие психические процессы, как восприятие, понимание и запоминание.

Следует также отметить, что и полевое описание лексики является очень важным при анализе процесса текстообразования, потому что в текстовых словесно-ассоциативных полях слова группируются и на основании смысловой общности, и по наличию семантических связей, что позволяет следить за тем, как эти поля участвуют в процессе создания текстов.

Первично в сознании автора-создателя текста появляется тема, идея и образы, их отражающие. Они передаются при помощи ассоциирующихся с ними слов. Но эти слова не существуют отдельно, они вступают в семантические связи между собой, образуя словосочетания и предложения, из которых впоследствии образуется цельный и связный текст.

В сознании каждого из нас присутствует определенный набор понятий и образов, связанных с окружающей нас действительностью. И как только появляется стимул, эти понятия и образы реализуются при помощи слов. Но они не появляются одни, они влекут за собой и другие понятия и образы, с ними связанные. То же самое происходит и в тексте. Создавая его, автор 
опирается на ключевые слова, помогающие ему раскрыть основную тему. Эти ключевые слова и выступают в роли стимулов для ассоциативного процесса, при помощи которого создается текст.

Механизм лексического ассоциирования основывается на том, что лексикон, как часть языкового устройства, должен быть готов к порождению текстов. Такая готовность должна обеспечиваться организацией лексикона в сознании говорящего (Клименко, 2002), а также, по утверждению А. Е. Супруна, “ассоциативные связи слова имеют текстообразующую сущность, потенциально направлены на порождение и восприятие текстов” (Супрун, Клименко, 2017).

Выводы и перспективы дальнейших исследований. Текстообразующая функция словесно-ассоциативных полей очень важна и по той причине, что восприятие текста во многом зависит от тех факторов, при помощи которых текст был образован. Художественные тексты допускают (а порой даже предполагают) различия в их понимании. Эти различия возможно выявить лишь при помощи ассоциаций. У каждого читателя они будут свои, так как каждый читающий и воспринимающий текст интерпретирует его на основании своих личных переживаний, прошлого опыта, уровня образованности, эмоциональности и т.д. И задача любого автора - создать текст, который будет интересен максимальному числу потенциальных читателей. Таким образом, ассоциативная природа текстообразования очевидна: автор предлагает свои стимулы и ассоциации читателю, который, в свою очередь, объединяет их со своими. Так образуется текстовое ассоциативное поле, а в последствии и сам текст.

Исходя из этого, ассоциативное поле со всеми лексическими связями, присутствующими в нем, можно рассматривать как своеобразный текст, хотя оно и имеет свою собственную организацию.

\section{ЛИТЕРАТУРА}

Болотнова, Н.С. (2003). Филологический анализ текста. Ч. IV: Методы исследования. Томск: Издательство Томского государственного педагогического университета.

Верескун, С. А. (2012). Виды ассоциативных полей в когнитивных исследованиях. Известия Южного федерального университета. Филологические науки, 2, 125-131.

Гальперин, И. Р. (2006). Текст как объект лингвистического исследования (изд. 4-е, стереотипное). Москва: КомКнига.

Караулов, Ю. Н. (2015). Ассоциативный анализ: новый подход к интерпретации художественного текста. Вопросы психолингвистики. 3 (25), 14-35. Москва.

Карпенко, С. М. (2009). К вопросу о типах ассоциативных доминант в лексической структуре поэтического текста (на материале лирики Н. С. Гумилева). Вестник Томского государственного педагогического университета, 4, 112-115.

Клименко, А. П. (1974). Лексическая системность и ее психолингвистическое изучение: учеб. пособ. Минск: МГПИИЯ.

Клименко, А. П. (2002). Текстообразующая направленность ассоциирования Форма, значение и функции единии языка и речи: Материаль II научной международной конференции. 33-34. Минск.

Сахарный, Л. В. и Штерн, А. С. (1988). Набор ключевых слов как тип текста. Лексические аспекты в системе профессионально-ориентированного обучения иноязычной речевой деятельности. 34-51. Пермь: Пермский политехнический ун-т.

Супрун, А. Е. и Клименко, А. П. (2017). Проблемы изучения лексической структуры текста. Текст в языке, речи, культуре: сб. науч. ст. 7-15. Минск: РИВШ.

ИСТОЧНИК ИЛЛЮСТРАТИВНОГО МАТЕРИАЛА

Wheelock, L. The Legend of the Christmas Tree (2006) Взято c http://www.mainlesson.com/ display.php?author=bailey\&book=hour\&story=tree 


\section{REFERENCES}

Bolotnova, N.S. (2003). Fylolohycheskyj analyz teksta. Ch. IV: Metody yssledovanyia. Tomsk: Yzdatel'stvo Tomskoho hosudarstvennoho pedahohycheskoho unyversyteta.

Vereskun, S. A. (2012). Vydy assotsyatyvnykh polej v kohnytyvnykh yssledovanyiakh. Yzvestyia Yuzhnoho federal'noho unyversyteta. Fylolohycheskye nauky, 2, 125-131.

Hal'peryn, Y. R. (2006). Tekst kak ob'ekt lynhvystycheskoho yssledovanyia (yzd. 4-e, stereotypnoe). Moskva: KomKnyha.

Karaulov, Yu. N. (2015). Assotsyatyvnyj analyz: novyj podkhod k ynterpretatsyy khudozhestvennoho teksta. Voprosy psykholynhvystyky. 3 (25), 14-35. Moskva.

Karpenko, S. M. (2009). K voprosu o typakh assotsyatyvnykh domynant v leksycheskoj strukture poetycheskoho teksta (na materyale lyryky N. S. Humyleva). Vestnyk Tomskoho hosudarstvennoho pedahohycheskoho unyversyteta, 4, 112-115.

Klymenko, A. P. (1974). Leksycheskaia systemnost' y ee psykholynhvystycheskoe yzuchenye: ucheb. posob. Mynsk: MHPYYYa.

Klymenko, A. P. (2002). Tekstoobrazuiuschaia napravlennost' assotsyyrovanyia. Forma, znachenye y funktsyy edynyts iazyka y rechy: Materyaly II nauchnoj mezhdunarodnoj konferentsyy. 33-34. Mynsk.

Sakharnyj, L. V. i Shtern, A. S. (1988). Nabor kliuchevykh slov kak typ teksta. Leksycheskye aspekty v systeme professyonal'no-oryentyrovannoho obuchenyia ynoiazychnoj rechevoj deiatel'nosty. 34-51. Perm': Permskyj polytekhnycheskyj un-t.

Suprun, A. E. i Klymenko, A. P. (2017). Problemy yzuchenyia leksycheskoj struktury teksta. Tekst v iazyke, rechy, kul'ture: sb. nauch. st. 7-15. Mynsk: RYVSh.

Дата надходження до редакиії 02.02.2018 р. Ухвалено до друку 27.04.2018 p. 